\title{
A 'Movement Screening Test' of Functional Control Ability in Female Recreation Golfers and Non-Golfers over the Age of 80 Years: A Reliability Study
}

\author{
Nicholas Webb ${ }^{1}$,, Keira Rowsome ${ }^{1}$, Sean Ewings ${ }^{1}$, Mark Comerford ${ }^{1,2}$, Maria Stokes ${ }^{1,3}$ \\ and Sarah Mottram 1,2,3,* \\ 1 School of Health Sciences, University of Southampton, Southampton SO17 1BJ, UK; \\ Nicholas.j.webb@btinternet.com (N.W.); keira.rowsome@gmail.com (K.R.); sean.ewings@soton.ac.uk (S.E.); \\ mark@movementperformancesolutions.com (M.C.); M.Stokes@soton.ac.uk (M.S.) \\ 2 Movement Performance Solutions Ltd., Bristol BS1 3AE, UK \\ 3 Arthritis Research UK Centre for Sport, Exercise and Osteoarthritis, Nottingham NG7 2UH, UK \\ * Correspondence: sarah@movementperformancesolutions.com; Tel.: +44-(0)23-8059-6868
}

Received: 19 September 2018; Accepted: 1 November 2018; Published: 7 November 2018

\begin{abstract}
Assessing function in elderly populations predominantly aims to quantify the risk of falling. Current assessment methods do not consider changes associated with aging in movement coordination patterns and the ability to control movement. The aim of this study was to examine the intra-rater reliability of a 'Movement Screening Test' (MST) in females over 80 years across a range of physical activity levels, who were golfers and non-golfers. Female recreational golfers $(N=21)$ and non-golfers $(N=10)$ aged 80 to 87 years performed the MST. The MST consists of three tests: Test 1, sit to stand with arm lift; Test 2, trunk lean with knee bend and opposite arm lift; Test 3, chest rotation with neutral head and pelvis. Videos of the MST were analyzed and scored according to specific criteria. The videos were reviewed on two separate occasions to quantify the intra-rater reliability of scoring of the MST. Intra-rater reliability $(\kappa)$ of the MST demonstrated substantial agreement for $11 / 23$ criteria $(\kappa=0.65$ and to 0.78$)$ and excellent agreement for $9 / 23$ criteria ( $k=0.81$ to 1 ). Therefore, the reliability of the MST for women aged 80 years and over was established. The MST test and scoring system may be further refined to improve reliability. Further investigations could explore coordination patterns in older people, how these relate to various aspects of musculoskeletal function, and how they vary between different populations.
\end{abstract}

Keywords: recreational golfers; female; movement screening; aging; functional ability

\section{Introduction}

The World Health Organization suggests that the number of adults over the age of 80 is set to quadruple by the year 2050 [1]. Health expenditure for adults over the age of 75 is approximately 5.5 times higher than for their younger counterparts aged 25-34 in industrialized countries [2].

Much of the health care costs associated with aging are due to the increased risk of falls and associated injuries [3]. The frequency of falling in the older population increases with age with one in three people over the age of 65 and half of adults over 80 falling at least once a year [4]. The reason for falling is often described as multi-factorial [5], though age-related reductions in strength [6,7], balance [8-10], and postural stability [9,10], as well as reduced activity levels [11], significantly contribute to falling. The most significant reductions tend to occur in adults over the age of 80 years and have been reported to be more prevalent in women than in men [4,11-13]. 
The reduction in activity and subsequent physiological changes in older adults has led to a host of screening tools being developed to measure a number of physical performance characteristics. The Senior Fitness Test [14], Timed up and Go (TUG) Test [15], Berg Balance Test [16], and the Functional Reach Test [17] are just a few of many tests that are used to assess the physical performance of older adults. However, these quantitative measures do not focus on movement patterns that influence the scores, and so do not provide health professionals with specific information regarding rehabilitation strategies.

These tests are also predominantly used to identify potential falls risks in older adults and, whilst they aim to reflect functional performance, they do not assess the ability of individuals to coordinate their movements.

Movement is clearly complex and influenced by many interactions. An adapted model of the dynamic systems theory has been presented by Dingenen [18]. This model proposes that an individual's movement pattern emerges out of the interaction of three domains. These domains include factors related to the person (e.g., age, co-morbidities), the task being performed (e.g., sitting to standing, walking), and the environment or context in which it is performed (walking within the confines of home or outdoors). Clinical interventions can focus on any of these domains in order to produce a clinical outcome. However, a focus upon the movement pattern emerging from these interactions is of interest to both clinicians and researchers [18]. The value of movement and the factors that influence movement coordination strategies are now being used to support participation and maintain health in the older population [19].

An ability to consciously demonstrate variation in the co-ordination strategies employed to achieve a movement outcome can be considered to illustrate the possession of choice in movement $[18,20]$. For example, when transitioning from sitting to standing, an individual may choose to employ a movement strategy that is reliant upon a large amplitude of sagittal plane movement at the hip, whereas in their next demonstration of the same action, they employ a strategy in which there is approximately equal contribution from the hip and knee. The capacity to alter at will which, of all the available strategies, is employed is proposed to act as a marker of the health of the individual's movement system [18,20]. Cognitive movement control assessment evaluates an individual's ability to cognitively coordinate movement at a specific joint or region (site) in a particular plane of movement (direction), under low- and high-threshold loading, often during multi-joint tests within functionally orientated tasks [21,22].

These tests have demonstrated good to excellent inter- and intra-rater reliability [22,23]. Adopting this movement coordination approach to screen older adults for loss of choices in movement, may aid in targeting rehabilitation programs and help promote the importance of maintaining activity levels in older populations. Some evidence is emerging of the benefits of motor learning exercises on mobility performance in older adults [24-26].

A battery of cognitive movement control tests, designed for older people, was described by Rowsome et al. [23]. Overall, intra-rater reliability for a group of participants aged 65-79 years was acceptable, but certain assessment criteria were identified as being less reliable than others. Recommendations were made for the refinement of some criteria to improve the reliability of the screening tool, so the present study examined the reliability of a refined tool in older people over 80 years. Refining this movement screen to identify coordination strategies in older adults may aid in targeted rehabilitation programs and help promote the importance of maintaining movement choices in older populations.

The primary aim of this study was to determine the intra-rater reliability of a Movement Screening Test (MST) in golfers and non-golfers females aged over 80 years, across a range of physical activity levels. 


\section{Materials and Methods}

\subsection{Participants}

Thirty-one participants were included in the study, 10 non-golfers and 21 golfers. Golfers were recruited by contacting local golf clubs in Hampshire and West Sussex and displaying information about the study. To recruit non-golfing participants, posters were sent, and short presentations were delivered to groups at local churches, luncheon clubs, and libraries. Fifty potential participants were contacted: 11 non-golfers and 8 golfers did not meet the inclusion and exclusion criteria. The study was approved by the Faculty of Health Sciences ethics committee, University of Southampton, ethics number 14,158. All procedures performed were in accordance with the ethical standards of the institutional research committee and with the 1964 Helsinki declaration and its later amendments.

In order to be deemed suitable for the study, all participants answered a screening questionnaire which included a section adapted from the Physical Activity Scale for the Elderly (PASE) [27] to ensure the non-golfing participants did not regularly partake in moderate levels of physical activity. Examples of moderate activities given in the PASE were golf without a cart, ballroom dancing, doubles tennis. Golfers were included if they had been playing golf for more than two years and regularly played 18 holes of golf at least once per week.

All participants were screened over the phone prior to participation in the study. Participants were excluded if they had: musculoskeletal disorders that limited their daily activities; joint replacement in the previous five years; cardio respiratory disorders including history of myocardial infarction; uncontrolled blood pressure; chronic obstructive pulmonary disease; systemic disorders such as uncontrolled diabetes; history of malignancy within the previous five years; neurological conditions such as Parkinson's, Multiple Sclerosis, and Rheumatoid Arthritis. If known, height and weight were asked to determine the body mass index (BMI). A BMI $>35 \mathrm{~kg} / \mathrm{m}^{2}$ excluded participants from the study.

\subsection{Procedure}

The testing procedures were carried out at either a local golf club or at the University of Southampton, and the testing procedures included in the present study were completed in $20 \mathrm{~min}$. Prior to data collection, all participants were asked to refrain from any strenuous physical activity in the $48 \mathrm{~h}$ prior to testing. On arrival, all participants completed a consent form. Prior to testing, all participants' height and body mass were recorded.

\subsection{Movement Screening Tests}

All participants completed the movement screening tests outlined in Appendix A. Figure 1 shows the three tests being performed. The participants were videoed using a handheld recording device (Samsung Galaxy Nexus) for offline assessment of the test. Test 1 was performed twice by each participant, allowing the test to be recorded in the frontal (dominant side) and sagittal planes. Test 2 was recorded in the frontal plane, allowing the dominant arm to be viewed. Test 3 was recorded in the sagittal plane. Prior to commencing the tests, the researcher explained in detail the objective of each test, and the participants were shown videos of each test being performed. The participants were allowed up to two practice attempts so that they understood how to perform the movements. Specific standardized instructions were then given verbally whilst the participant performed each test. 

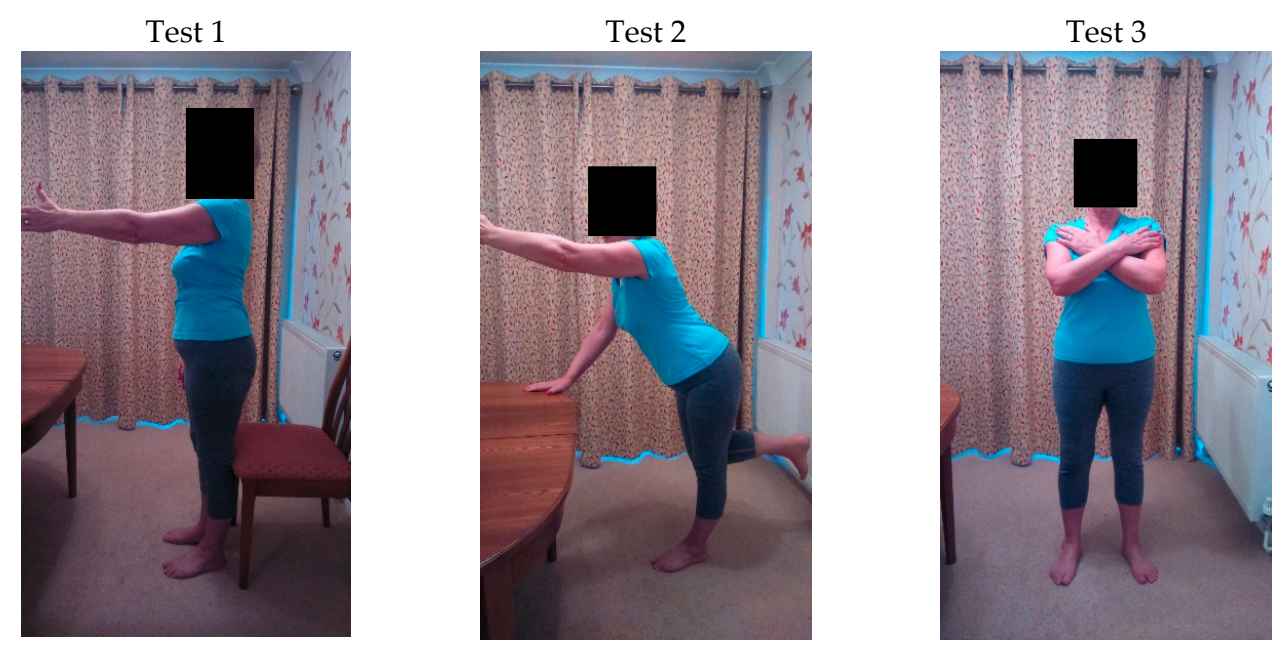

Figure 1. Participant carrying out the Movement Screening Tests: Test 1, sit to stand with arm lift; Test 2, trunk lean with knee bend and opposite arm lift; Test 3, chest rotation with neutral head and pelvis.

\subsection{Scoring System}

After all participants had completed the MST, the videos were reviewed and scored according to a scoring system (see Appendix A). This scoring system was adapted with permission from the original MST [23]. The tests were then reviewed and scored again two weeks later to allow intra-rater reliability to be assessed. As the test is designed to measure impairment, a score of 0 is rated a pass, and a fail is rated as 1 . The participants were scored for each individual test, and a total score out of 23 points was also calculated.

\subsection{Statistical Analysis}

All data were analyzed using IBM SPSS (version 22, SPSS Inc., Chicago, IL, USA), Microsoft Excel, and Stata and were initially tested for normality using the Shapiro-Wilks test.

Movement Screening Test: Intra-rater reliability. Cohen's Kappa coefficient $(\mathrm{k})$ including $95 \%$ confidence intervals and percentage agreement was used to establish the reliability of each individual test criterion for the MST. Kappa is commonly used when ratings are on a nominal scale [28] and describes the agreement beyond chance, whereas percentage agreement does not take this into account. According to McHugh [29], Kappa value ranges between 0.41 and 0.6 are considered moderate, between 0.61 and 0.8 are considered substantial, and between 0.81 and 1 are considered excellent.

The reliability of the overall movement screen test scores was assessed using the intra-class correlation co-efficient (ICC) [30]. The ICC $(1,1)$ model was used (with participants as the only effect). According to Fleiss [30], ICC values $>0.75$ are considered excellent, between 0.4 and 0.74 good to fair, and $<0.4$ poor.

\section{Results}

\subsection{Participant Characteristics}

Participant characteristics for the golfers and non-golfers are presented in Table 1. No significant differences were found for height, weight, and BMI $(p>0.05)$ between the two groups. A significant difference for age $(p<0.05)$ was observed, with the golfers being older than the non-golfers. Results from the screening questionnaire described the activity levels of the golfers and non-golfers. Of the 21 golfers (who averaged two rounds per week, and five of whom played three times per week) one also took part in 1-2 days of strenuous activity per week and all 21 took part in moderate activity each week (mean 2.5 days per week) with two taking part in four days of moderate activity 
per week; in addition, ten took part in other forms of light recreational activity in addition to golf, with a mean of approximately 2.5 days per week. As for non-golfers, none of them took part in any moderate or strenuous activity; of the 10 non-golfers, five took part in light recreational activity each week (three participants took part on three days in any week, two on just one day in any week).

Table 1. Participant characteristics: Age is presented as median (interquartile range). Height, weight, and body mass index (BMI) are presented as mean \pm SD with mean difference (confidence intervals).

\begin{tabular}{|c|c|c|c|c|}
\hline Characteristics & Golf $(N=21)$ & Non-Golf $(N=10)$ & $\begin{array}{c}\text { Mean Difference } \\
(95 \% \mathrm{CI})\end{array}$ & Significance \\
\hline $\begin{array}{l}\text { Age (Years) } \\
\text { Range }\end{array}$ & $\begin{array}{l}83(3) \\
80-87\end{array}$ & $\begin{array}{c}80.5(1.25) \\
80-83\end{array}$ & N/A & $p=0.004$ * \\
\hline $\begin{array}{l}\text { Height }(\mathrm{m}) \\
\text { Range }\end{array}$ & $\begin{array}{c}1.58 \pm 0.04 \\
1.51-1.65\end{array}$ & $\begin{array}{c}1.57 \pm 0.05 \\
1.46-1.66\end{array}$ & $-0.01(-0.05-0.02)$ & $p=0.38$ \\
\hline $\begin{array}{l}\text { Weight }(\mathrm{kg}) \\
\text { Range }\end{array}$ & $\begin{array}{c}62.3 \pm 9.22 \\
46.9-78.8\end{array}$ & $\begin{array}{c}66.2 \pm 12.7 \\
53.4-93.8\end{array}$ & $3.87(-4.34-12)$ & $p=0.34$ \\
\hline $\begin{array}{l}\text { BMI }\left(\mathrm{kg} / \mathrm{m}^{2}\right) \\
\text { Range }\end{array}$ & $\begin{array}{c}24.7 \pm 3.56 \\
18.8-31.9\end{array}$ & $\begin{array}{c}26.8 \pm 4.42 \\
20.7-34\end{array}$ & $2.05(-0.97-5.0)$ & $p=0.34$ \\
\hline
\end{tabular}

${ }^{*}$ Denotes significance $p<0.05$.

\section{Percentage Agreements}

The percentage agreements for individual test criterions ranged from 87 to $100 \%$, with a mean overall agreement of $95 \%$. Only two of the 23 criteria fell below $90 \%$ (Test 1.1a and 3.3). Six criteria (Test 1.4a, 1.1b, 1.3b, 2.4, 2.6, 3.5) demonstrated 100\% agreement. The percentage agreements for each test are shown in Table 2. A graphical representation in Figure 2 demonstrates clearly the percentage agreement for each of the test criteria, with values close to or on the outer edge of the graph representing excellent agreement.

Table 2. Reliability of individual test scores; \% agreements and Cohen's kappa with 95\% confidence intervals.

\begin{tabular}{ccc}
\hline Test & \% Agreement & Kappa \\
\hline $1.1 \mathrm{a}$ & 87 & $0.74(0.50-0.97)$ \\
$1.2 \mathrm{a}$ & 94 & $0.71(0.33-1.00)$ \\
$1.3 \mathrm{a}$ & 97 & $0.65(0.02-1.00)$ \\
$1.4 \mathrm{a}$ & 100 & $1(1.00-1.00)$ \\
$1.5 \mathrm{a}$ & 94 & $0.85(0.65-1.00)$ \\
$1.6 \mathrm{a}$ & 94 & $0.81(0.57-1.00)$ \\
$1.7 \mathrm{a}$ & 90 & $0.73(0.45-1.00)$ \\
$1.1 \mathrm{~b}$ & 100 & $1(1.00-1.00)$ \\
$1.2 \mathrm{~b}$ & 97 & $0.78(0.37-1.00)$ \\
$1.3 \mathrm{~b}$ & 100 & $1(1.00-1.00)$ \\
$1.4 \mathrm{~b}$ & 90 & $0.87(0.69-1.00)$ \\
2.1 & 97 & $0.87(0.69-1.00)$ \\
2.2 & 97 & $0.65(0.02-1.00)$ \\
2.3 & 97 & $0.65(0.02-1.00)$ \\
2.4 & 100 & $1(1.00-1.00)$ \\
2.5 & 90 & $0.73(0.49-0.97)$ \\
2.6 & 100 & $\mathrm{NA}$ \\
2.7 & 90 & $0.66(0.32-1.00)$ \\
3.1 & 97 & $0.93(0.81-1.00)$ \\
3.2 & 90 & $0.67(0.34-1.00)$ \\
3.3 & 87 & $0.73(0.49-0.97)$ \\
3.4 & 97 & $0.47(-0.12-1.00)$ \\
3.5 & 100 & NA \\
\hline
\end{tabular}




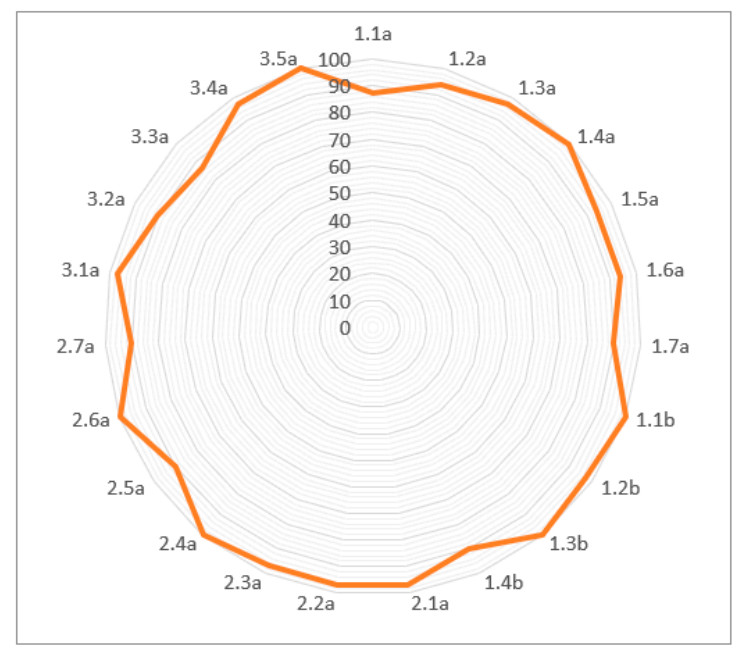

Figure 2. Radar graph showing the percentage agreement for individual test criteria (\%).

\subsection{Kappa Values}

Kappa values for each test criterion ranged from 0.47 to 1 . Only one of the 23 screening criteria (test 3.4) demonstrated kappa values below 0.6 (0.47), demonstrating moderate agreement. However, $97 \%$ agreement was observed for this test. Eleven of the 23 criteria demonstrated kappa values between 0.65 and 0.78 , indicating substantial agreement. Nine criteria reported kappa values between 0.81 and 1, which were considered excellent. Kappa values for two criteria, test 2.6 and 3.5, were not reported (NA), as no fail (1) scores were reported for any of the participants.

All test criteria percentage agreements and Kappa values with $95 \%$ confidence intervals are presented in Table 2.

The intra-class correlation coefficient (ICC 1, 1) of the overall scores (total of the 23 criteria) was 0.74 with $95 \%$ confidence intervals, $0.53-0.86$. This demonstrates good agreement of the overall test score.

\section{Discussion}

The aging process has detrimental effects on our physiology and can fundamentally alter the way we move. Assessing movement choices in the elderly population may help direct prevention strategies and rehabilitation interventions to improve the physical function and prevent falls.

The intra-rater reliability $(k)$ of the MST demonstrated substantial to excellent agreement for all but one criteria (test 3.4). This is in line with other tests that aim to quantify functional ability in older populations with similar reliability values reported for the TUG, Berg Balance Scale, and Gait speeds [31].

To allow for observation of the movement patterns two weeks apart, observations were made from video recordings. This method of quantifying movement has proved problematic in other studies [22], as the camera set up does not allow freedom to assess all angles and distances. Mischiati et al. [22] also highlighted similar problems as those experienced in the present study, in that the ability to stabilize the body may take a few seconds when performing dynamic movements, and thus the scoring should reflect this. For example, in Test 2, the participants were asked to lift their hand and opposite foot. Reducing the base of support challenges the movement outcome. However, in some cases, this destabilization caused a momentary period of loss of control, though the participants were able to gain postural control after a few seconds. Therefore, the instruction on when to score the movement may need further clarification. Scoring the movement after a pre-determined time, for example, $3 \mathrm{~s}$, would help to standardize the scoring. This should be considered for future studies when determining inter-rater reliability. 
This study illustrates situations where it is not possible to assess agreement using Kappa ( $\kappa$ ). This phenomenon of high agreement but low Kappa scores was discussed by Cicchetti and Feinstein [32]. In the present study, for example, the scores for each participant were " 0 " in tests 2.6 and 3.5 , for which no fail (1) scores were reported for any of the participants. $k$ was therefore undefined; this is because there were no data relating to " 1 ", and so the agreement could not be assessed across all out-comes ( 0 and 1$)$. In such cases, $\mathrm{k}$ was presented as "N/A". Both these tests had $100 \%$ agreement on one level of the outcome, and no information regarding agreement on the other level of the outcome.

Two movement screening reliability studies report on intra-tester reliability using cognitive movement control tests. Mischiati et al. [22] concluded that both inter- and intra-rater reliability of tests in The Foundation Matrix are acceptable when rated by two experienced therapists. Overall, the test percentage agreement was $87 \%$ for inter-rater reliability, with $98 \%$ Rater 1, 94\% Rater 2 for test re-test reliability. ICCs were excellent within raters (Rater 1, 0.96; Rater 2, 0.88). The reliability for individual components of each test was more variable: intra-rater, $88-100 \%$ Rater 1, 75-100\% Rater 2. Cohen's Kappa values for intra-rater were 0.6-1.0 for Rater 1, $-0.1-1.0$ for Rater 2. Rowsome et al. [23] reported on intra-rater reliability in a similar battery of tests on thirty-one female recreational golfers, aged 65-77. The percentage agreement for each test ranged from 93.0 to $97.3 \%$, with an overall mean agreement of $95.5 \%$. The Kappa values for the test scores ranged from 0.35 to 0.90 . the percentage agreement for individual criteria ranged from 83.0 to $100.0 \%$, with kappa values ranging from 0.00 to 1.00 .

Changes were made to aspects of how the tests maneuvers were conducted and to the assessment criteria. Examples include: (i) amendments were made to score movement challenges with the dominant side only (direct comparison to the Rowsome study could not be made) (ii) changing the assessment criteria of test 3.1 from 'can they keep the head facing forward and control/prevent the head from turning or rotating to follow the upper trunk rotation?' to 'can they keep the head facing forward and control/prevent the head from turning or rotating throughout the $30^{\circ}$ of upper trunk rotation?' Rowsome et al. [23] reported 90.3\% agreement, whereas this paper determined a $97 \%$ agreement, demonstrating refinement of the MST for question 3.1.

\section{Limitations and Future Recommendations}

The ability to recruit older adults has also been shown to be problematic. Crombie et al. [11] demonstrated that females over the age of 75 years are reluctant to participate in research projects. Therefore, it may be that the participants recruited in this study were not typically representative of a female population over the age of 80 years. When comparing this age group with those of other studies [33], participants with a wide range of health complications were included by others, suggesting this feature is representative of this population. For future studies, it may be prudent to consider relaxing the inclusion and exclusion criteria to allow comparisons of groups that are more representative of an aging population; for example, by including those with joint replacements.

Now the reliability of the MST has been established, studies are warranted to test the validity of the MST against motion analysis, discriminant validity (to distinguish between groups), and sensitivity to change. Further research is needed to explore the relationship between the observed loss of movement choice, notated by the site, direction and threshold of uncontrolled movement, and other measures of musculoskeletal function.

\section{Conclusions}

The reliability of a movement screening test in female golfers and non-golfers over the age of 80 years has been established. The results illustrate the utility of the MST for observing coordination strategies and the ability to control movement in older people, which has been lacking in assessments for older people. Identifying variations in coordination strategies using the MST may aid in targeting rehabilitation programs to support participation and maintain health in the older population.

Author Contributions: Conceptualization, N.W., K.R., S.E., M.C., M.S., and S.M.; Formal analysis, N.W. and S.E.; Funding acquisition, M.S.; Investigation, N.W.; Methodology, N.W., K.R., S.E., M.C., M.S., and S.M.; Project 
administration, N.W. and M.S.; Resources, M.S.; Supervision, M.C., M.S., and S.M.; Visualization, N.W., S.E., M.S., and S.M.; Writing—original draft, N.W. and S.M.; Writing—review \& editing, N.W., K.R., S.E., M.C., M.S., and S.M.

Funding: This research was funded, in part, by Arthritis Research UK, grant number 20194.

Acknowledgments: The authors thank the participants for taking part in the study. Cams Hall Estate, Southwick Park, Hayling Island, and Corhampton Golf Clubs for helping with the participant recruitment and providing facilities. They also would like to thank Jessica Wooton, Alison Stockdale, and Simon Brown for technical assistance during data collection.

Conflicts of Interest: Sarah Mottram is an employee of and Mark Comerford is a consultant to Movement Performance Solutions Ltd. who educate and train sports, health, and fitness professionals to better understand, prevent, and manage musculoskeletal injury and pain that can impair movement and compromise performance in their patients, players, and clients. No other authors have any conflicts of interests to declare. No financial support or equities were provided by Movement Performance Solutions.

\section{Appendix A. Movement Screen Test Instructions and Scoring System}

Table A1. Movement Screen Test Instructions and Scoring System.

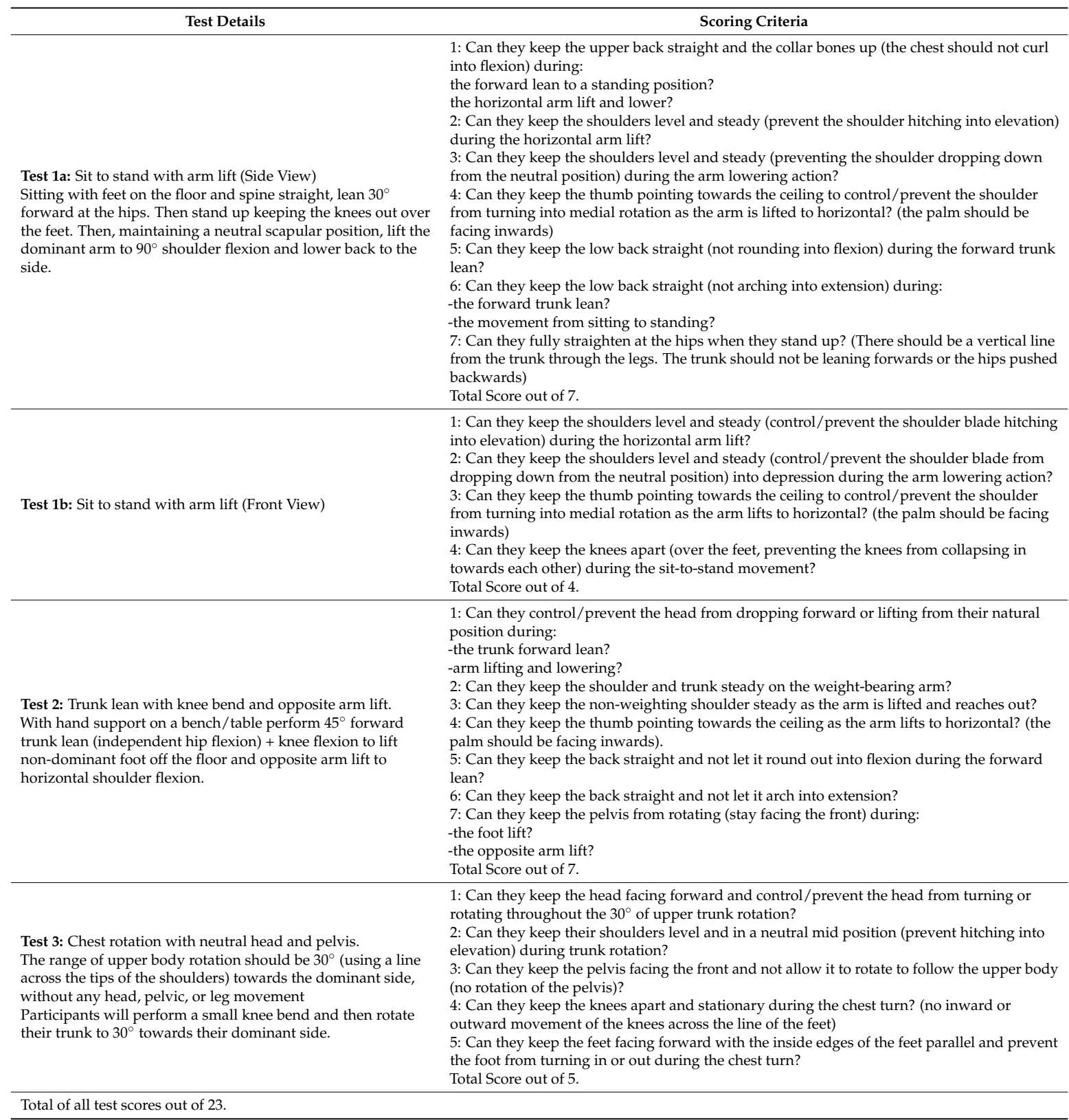




\section{References}

1. World Health Organization World Health Day-Aging and Health. 2012. Available online: http:/ / www.who. int/world-health-day/2012/toolkit/background/en/ (accessed on 16 November 2014).

2. Reinhardt, U. Does the aging of the population really drive the demand for health care? Health Aff. 2003, 22, 27-39. [CrossRef]

3. Tian, Y.; Thompson, J.; Buck, D.; Sonola, L. Exploring the System Wide Costs of Falls in Older People in Torbay. 2013. Available online: http:/ / www.kingsfund.org.uk/publications/exploring-system-wide-costsfalls-older-people-torbay (accessed on 18 November 2014).

4. Todd, C.; Skelton, D. What are the Main Risk Factors for Falls among Older People and What are the Most Effective Interventions to Prevent these Falls? Health Evidence Network Report; WHO Regional Office for Europe: Copenhagen, Denmark, 2004; Available online: www.euro.who.int/document/E82552.pdf (accessed on 15 November 2014).

5. Rubenstein, L.; Josephen, K. The epidemiology of falls and syncope. Clin. Geriatr. Med. 2002, 18, 141-158. [CrossRef]

6. Petrella, J.; Kim, J.; Tuggle, S.; Hall, S.; Bamman, M. Age differences in knee extension power, contractile velocity, and fatigability. J. Appl. Physiol. 2005, 98, 211-220. [CrossRef] [PubMed]

7. Granacher, U.; Gruber, M.; Gollhofer, A. Force production capacity and functional reflex activity in young and elderly men. Aging Clin. Exp. Res. 2010, 22, 374-382. [CrossRef] [PubMed]

8. Era, P.; Sainio, P.; Koskinen, S.; Haavisto, P.; Vaara, M.; Aromaa, A. Postural balance in a random sample of 7979 subjects aged 30 years and over. Gerontology 2006, 52, 204-213. [CrossRef] [PubMed]

9. Amiridis, I.; Hatzitaki, V.; Arabatzi, F. Age-induced modifications of static postural control in humans. Neurosci. Lett. 2003, 30, 137-140. [CrossRef]

10. Laughton, C.; Slavin, M.; Katdare, K.; Nolan, L.; Bean, J.F.; Kerrigan, D.C.; Phillips, E.; Lipsitz, L.A.; Collins, J.J. Aging, muscle activity, and balance control: Physiologic changes associated with balance impairment. Gait Posture 2003, 18, 101-108. [CrossRef]

11. Crombie, I.; Irvine, L.; Williams, B.; McGinnis, A.; Slane, P.; Alder, E.; McMurdo, M. Why older people do not participate in leisure time physical activity: A survey of activity levels, beliefs and deterrents. Age Aging 2004, 33, 287-292. [CrossRef] [PubMed]

12. British Heart Foundation. Interpreting the UK Physical Activity Guidelines for Older Adults (65+). Available online: http:/ / www.bhfactive.org.uk/userfiles/Documents/frailerolderadults.pdf (accessed on 18 November 2014).

13. Skelton, D.A.; Young, A.; Walker, A.; Hoinville, E. Physical Activity in Later Life: Further Analysis of the Allied Dunbar National Fitness Survey and the HEASAH; Health Education Authority, The Stationary Office: London, UK, 1999; pp. 40-58.

14. Jones, J.; Rikli, R. Measuring functional fitness of older adults. J. Act. Aging 2002, 2, 24-30.

15. Podsiadlo, D.; Richardson, S. The timed "Up \& Go": A test of basic functional mobility for frail elderly persons. J. Am. Geriatr. Soc. 1991, 39, 142-148. [PubMed]

16. Berg, K.O.; Wood-Dauphinee, S.L.; Williams, J.I.; Gayton, D. Measuring balance in elderly: Preliminary development of an instrument. Physiother. Can. 1989, 41, 304-311. [CrossRef]

17. Duncan, P.; Studenski, S.; Chandler, J.; Prescott, B. Functional Reach: Predictive validity in a sample of elderly male veterans. J. Gerontol. 1992, 47, M93-M98. [CrossRef] [PubMed]

18. Dingenen, B.; Blandford, 1.; Comerford, M.; Staes, F.; Mottram, S. The assessment of movement health in clinical practice: A multidimensional perspective. Phys. Ther. Sport 2018, 32, 282-292. [CrossRef] [PubMed]

19. Bauman, A.; Merom, D.; Bull, F.C.; Buchner, D.M.; Fiatarone Singh, M.A. Updating the Evidence for Physical Activity: Summative Reviews of the Epidemiological Evidence, Prevalence, and Interventions to Promote "Active Aging". Gerontologist 2016, 56, S268-S280. [CrossRef] [PubMed]

20. McNeill, W.; Blandford, L. Movement Health. J. Bodyw. Mov. Ther. 2015, 19, 150-159. [CrossRef] [PubMed]

21. Comerford, M.J.; Mottram, S.L. Kinetic Control: The Management of Uncontrolled Movement, 1st ed.; Elsevier: Amsterdam, The Netherlands, 2012.

22. Mischiati, C.; Comerford, M.; Gosford, E.; Swart, J.; Ewings, S.; Botha, N.; Stokes, M.; Mottram, S.L. Intra and Inter-Rater Reliability of Screening for Movement Impairments: Movement Control Tests from the Foundation Matrix. J. Sports Sci. Med. 2015, 14, 427-440. [PubMed] 
23. Rowsome, K.; Comerford, M.; Mottram, S.; Samuel, D.; Stokes, M. Movement Control Testing of Older People in Community Settings: Description of a Screening Tool and Intra-Rater Reliability; Working Papers in the Health Sciences; University of Southampton: Southampton, UK, 2016; Volume 1, pp. 1-12. Available online: https: / / www.southampton.ac.uk/wphs/current_issue.page (accessed on 27 April 2018).

24. Brach, J.S.; Van Swearingen, J.M.; Perera, S.; Wert, D.M.; Studenski, S. Motor learning versus standard walking exercise in older adults with subclinical gait dysfunction: A randomized clinical trial. J. Am. Geriatr. Soc. 2013, 61, 1879-1886. [CrossRef] [PubMed]

25. Brach, J.S.; Lowry, K.; Perera, S.; Hornvak, V.; Wert, D.M.; Studenski, S.; Van Swearingen, J.M. Improving motor control in walking: A randomized clinical trial in older adults with subclinical walking difficulty. Arch. Phys. Med. Rehabil. 2015, 96, 388-394. [CrossRef] [PubMed]

26. VanSwearingen, J.M.; Studenski, S.A. Aging, motor skill, and the energy cost of walking: Implications for the prevention and treatment of mobility decline in older persons. J. Gerontol. A Biol. Sci. Med. Sci. 2014, 69, 1429-1436. [CrossRef] [PubMed]

27. Washburn, R.; MacAuley, E.; Katula, J.; Mihalko, S.L.; Boileau, R.A. The Physical Activity Scale for the Elderly (PASEP): Evidence for Validity. J. Clin. Epidemiol. 1999, 52, 643-651. [CrossRef]

28. Cohen, J. A coefficient of agreement for nominal scales. Educ. Psychol. Meas. 1960, 20, 37-46. [CrossRef]

29. McHugh, M. Inter-Rater Reliability. The Kappa Statistic. Available online: http://www.ncbi.nlm.nih.gov/ pmc/articles/PMC3900052/ (accessed on 1 October 2015).

30. Fleiss, J. Reliability of Measurement in the Design and Analysis of Clinical Experiments; Wiley and Sons: New York, NY, USA, 2011; pp. 1-33.

31. Steffen, T.; Hacker, T.; Mollinger, L. Age and Gender-Related test performance in community dwelling elderly people: Six minute walk test, Berg balance scale, Timed up and go test, and Gait speeds. Phys. Ther. 2002, 82, 128-137. [CrossRef] [PubMed]

32. Cicchetti, D.V.; Feinstein, A.R. High agreement but low kappa: II. Resolving the paradoxes. J. Clin. Epidemiol. 1990, 43, 551-558. [CrossRef]

33. Chiu, A.; Yeung, S.; Lo, S. A comparison of four functional tests in discriminating fallers from non-fallers in older people. Disabil. Rehabil. 2003, 25, 45-50. [CrossRef] [PubMed]

(C) 2018 by the authors. Licensee MDPI, Basel, Switzerland. This article is an open access article distributed under the terms and conditions of the Creative Commons Attribution (CC BY) license (http://creativecommons.org/licenses/by/4.0/). 